\title{
MOVIMIENTOS SOCIALES Y EXPANSIÓN URBANA: LAS OCUPACIONES DE TIERRA EN LA CIUDAD DE RESISTENCIA (ARG)
}

La autora es arquitecta (UNNE, Argentina), magíster en Epistemología y Metodología de la Investigación Científica (UNNE, Argentina) y docente e investigadora de la UNNE, Argentina.

RESUMEN. Este trabajo tiene su origen en una investigación sobre un conjunto de casos de ocupaciones de tierra urbana producidos en los últimos años en Resistencia, ciudad capital de la provincia del Chaco, situada en el NE Argentino.

Las ocupaciones de tierra en Resistencia como fenómeno urbano no es nuevo, ni mucho menos, pero las ocupaciones han cambiado en términos fundamentalmente cualitativos. Para ilustrar esto, el artículo presenta detalladamente un caso que se constituyó en el punto de inflexión: la ocupación de los terrenos denominados La Rubita.

El artículo sostiene que las ocupaciones de tierra en Resistencia pueden considerarse movimientos sociales con importantes efectos territoriales y políticos transformadores de la ciudad y la nueva forma en que se están produciendo las ocupaciones de tierra es un indicador de profundas transformaciones sociales.

ABSTRACT. SOCIAL MOVEMENTS AND URBAN EXPANTION: Lands Invasion in Resistencia City, Argentina.

This article is based on a research on urban land invasion cases that occurred few years ago in Resistencia, the capital city of the Chaco province, Northeast of Argentina. It is argued that land invasions in the city, as an urban phenomenon, it is not new. It has changed the matter of the quality of these actions. It is argued that land invasions have been considered as social movements, which has political and territorial transformation upon the city. It also mentions that a new trend of land invasions have emerged as an indicator of deep current social changes. To illustrate that, the land of 'La Rubita' has been chosen as a case study. This contains the main features of that peculiar social movement.

\section{Introducción}

Este trabajo tiene su origen en una investigación sobre un conjunto de casos de ocupaciones de tierra urbana producidos en los últimos años en la ciudad intermedia de Resistencia, capital de la provincia del Chaco situada en el NE Argentino.[1]

Cuadro 1. Muestra de las ocupaciones estudiadas

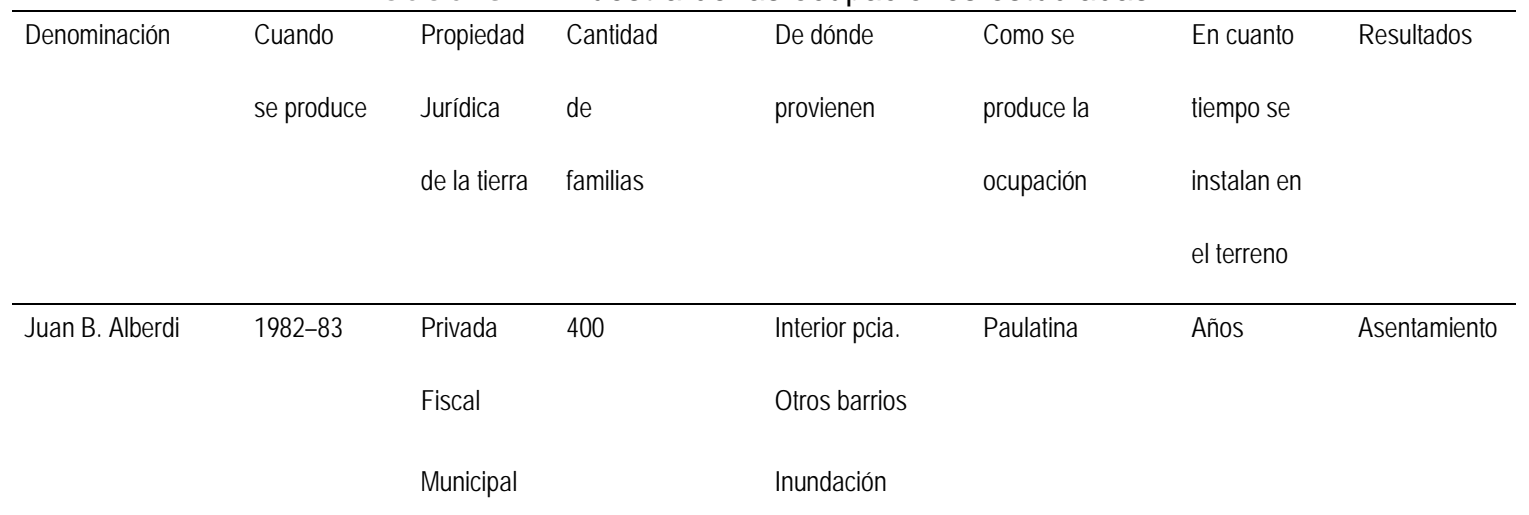




\begin{tabular}{|c|c|c|c|c|c|c|c|}
\hline Lote 202 & $1982-83$ & Privada & 600 & “ & $\begin{array}{l}\text { Inicialmente } \\
\text { repentina }\end{array}$ & días[2] & Asentamiento \\
\hline $\begin{array}{l}\text { Villa Luzuriaga } \\
\text { ampliación }\end{array}$ & 1986 & Privada & 113 & $"$ & Paulatina & Años & Asentamiento \\
\hline Villa Marin & 1989 & Privada & 100 & $"$ & Paulatina & Años & Asentamiento \\
\hline La Rubita & $03 / 97$ & $\begin{array}{l}\text { Ejercito } \\
\text { Nacional }\end{array}$ & 500 & $"$ & Repentina & 1 semana & $\begin{array}{r}\text { Expulsión / } \\
\text { relocalización }\end{array}$ \\
\hline Villa Río Negro & $02 / 98$ & Priv. & 25 & Otros barrios & Repentina & Dos días & Asentamiento \\
\hline Lote 133 & $05 / 98$ & Priv. & 280 & $\begin{array}{l}\text { Interior pcia. } \\
\text { Otros barrios } \\
\text { inundación }\end{array}$ & Repentina & Diez días & Asentamiento \\
\hline
\end{tabular}

Fuente: Elaboración propia.

Las ocupaciones de tierra en Resistencia como fenómeno urbano no es nuevo, ni mucho menos, gran parte de la ciudad está constituida por barrios que se originaron en asentamientos ilegales de población.

Pero las ocupaciones han cambiado en términos cuantitativos y cualitativos.[3] Este es el núcleo de este artículo, y para ilustrar esto presentaré detalladamente un caso que se constituyó en el punto de inflexión en los procesos de ocupación de tierras urbana: la ocupación de los terrenos denominados La Rubita y un conjunto de reflexiones en relación con las acciones de los pobladores como forma dominante de expansión urbana en Resistencia en la actualidad.

\section{EL CONTEXTO DE LAS OCUPACIONES DE TIERRA}

Aproximadamente el $15 \%$ de los habitantes de Resistencia[4] viven en situación irregular-sin servicios,[5] en asentamientos originados en ocupaciones, el $41 \%$ de terrenos originariamente fiscales y el $59 \%$ de terrenos originariamente privados.

La ciudad de Resistencia, siguiendo un proceso que se observa en la mayoría de las ciudades intermedias en toda América Latina, está sufriendo un acelerado crecimiento (de 8.000 a 10.000 personas/ año) producto de la combinación de la migración rural, por la crisis de la producción agraria, y la re-inmigración de chaqueños que vivían en otras ciudades argentinas y que ante el desempleo están volviendo, dándose un proceso inverso a lo que fue la metropolización de mediados de siglo XX.

Entre los años '70 y fines de los '80 la producción estatal de vivienda masiva construida con financiación del FONAVI[6] constituyó la respuesta al déficit de vivienda, provocado por la fuerte inmigración de población rural producto de la prolongada crisis agrícola que padece la provincia del Chaco.

A partir de los '90, aunque persiste o se han incrementado los procesos de migración poblacional hacia la ciudad capital de la provincia, la planificación y producción estatal de viviendas se ha transformado, reducido y/o reorganizado.

La crisis que se inició a mediados de los setenta en los países centrales, con impacto en nuestros países en los '80, afectó a las instituciones del llamado estado benefactor en la medida que involucró un re acomodamiento político de algunas instituciones de éste. Me refiero específicamente a instituciones que favorecieron una redistribución que posibilitó el acceso a amplios sectores de la 
población al consumo de bienes y servicios, y que en su momento[7] constituyó una ruptura con las instituciones de beneficencia, implementando el concepto de seguridad social.[8] Es decir, un conjunto de instituciones que crearon derechos garantizados jurídicamente y fueron incorporados como derechos adquiridos en la conciencia de la población (Isuani: 1991).

Actualmente los planes de viviendas se realizan con el sistema de co-financiación[9] y la gestión es realizada por organizaciones intermedias, gremios, etc., consecuentemente los desocupados o no sindicalizados, que constituyen un amplio sector de la población, quedan al descubierto en el tema habitacional.

En este contexto, las acciones de los pobladores destinadas a resolver sus problemas habitacionales, toman una nueva relevancia.

\section{LAS OCUPACIONES DE TIERRA Y "LOS SIN TECHO"}

Con asentamientos[10] originados en ocupaciones de tierra, me refiero a una configuración territorial urbana producto de la forma cómo resuelven su problema de vivienda los sectores marginados urbanos,[11] originados en ocupaciones de tierra estatales o privadas, constituyen un fenómeno bastante generalizado en toda Latinoamérica (tradicionalmente se los denominaba villas miserias, favelas, pueblos nuevos, cantegrille, etc.) y han sido bastamente estudiados, tanto desde las distintas miradas sobre la marginalidad como desde las distintas perspectivas del crecimiento urbano.

Las ocupaciones de terrenos por parte de grupos de pobladores, no es una situación nueva. La novedad es que estos procesos se han intensificado notablemente en ciudades de escala intermedia - como lo es la ciudad de Resistencia - a la vez que se detecta un retroceso en el incremento de la población en las grandes metrópolis.[12]

La expresión ocupación de tierras hace referencia a la apropiación para su uso de una porción de terreno urbano cuyos propietarios pueden ser algún aparato del estado —esos son los terrenos fiscales-, un particular que no resida en el lugar, o instituciones sociales tales como la Iglesia, etc.

La tierra, es tierra urbana, es decir, suelo mas la posibilidad de acceso a infraestructura —agua corriente, electricidad-, además de cierto equipamiento educacional, de salud, de recreación, etc.

Los "sin techo" - tal como son denominados en las crónicas de los diarios que dan cuenta de las ocupaciones, pertenecen al denominado sector ocupacional informal, pocos disponen de trabajos estables, la gran mayoría hace trabajos transitorios y mal remunerados para subsistir.[13] Las ocupaciones de tierra son fundamentadas por la mayoría "por no tener donde vivir" o "estar amontonados compartiendo viviendas en casas de familiares".[14]

Declaran que "convivían con otros familiares en numeroso contingente"[15]y enterados de la ocupación por un amigo o familiar, fueron encontrando una porción de terreno libre, o consiguieron comprar la "mejora".[16]

\section{DE LA REINVINDICACIÓN A LA TRANSFORMACIÓN DE LA ESTRUCTURA URBANA}

A comienzos de la década del 70, empezó a consolidarse la Escuela de Sociología Urbana Francesa en la que se pueden enmarcar los trabajos críticos de Castells, Topalov y Lojkine, y en nuestra región Coraggio y Da Mattos.[17] Y que constituyen una superación de la escuela marxista clásica en la medida en que retoman categorías del análisis urbano marxista clásico,[18] en análisis más complejos. Conceptos tales como la renta del suelo, y los roles (por acción u omisión) de los diferentes agentes sociales en la producción del espacio, privilegiando el accionar del estado en la valorización del suelo y fundamentalmente la visión de las ciudades como productos históricos en su materialidad física y su significación cultural, sirven para el análisis de la ciudad no solo como reflejo de la sociedad sino como producto social.

Para el análisis de los procesos de ocupaciones de tierra en Resistencia he partido del concepto de movimientos sociales urbanos, que se genera en el contexto de la revisión teórica mencionada, 
para explicar las crisis sociales, los conflictos y cambios sociales. Este concepto involucra las determinaciones del sistema productivo, pero incorporando categorías culturales y étnicas religiosas en la conformación de los movimientos sociales con relación a los procesos urbanos.

Se definen como movimientos sociales urbanos aquellas acciones colectivas que partiendo de contradicciones urbanas transforman la lógica dominante de producción del espacio y de organización de los procesos urbanos (Castells: 1988). La ocupación ilegal u originariamente ilegal para la autoconstrucción de viviendas constituye un objetivo clásico de los movimientos urbanos en América Latina, pero hay que analizar hasta qué punto estos movimientos transforman la estructura urbana. Los Movimientos sociales urbanos se articulan en relación a tres ejes, en principio y fundamentalmente el consumo colectivo, es decir, infraestructura urbana, por ejemplo vivienda, terrenos para vivienda, transporte, sanidad, educación, elementos en los que el Estado es decisivo (directa o indirectamente) en la producción, gestión y distribución. Otro eje es defender una identidad cultural, que puede estar ligada a las relaciones sociales de un barrio, una sub-cultura o clase que intenta establecer formas de articulación relativamente autónomas con respecto a la cultura dominante. $Y$ otro aspecto es la autogestión política o autonomía local, en la mayoría de los movimientos sociales urbanos que se desarrollan y tienen éxito existe una dimensión política subyacente y que a veces es expresada conscientemente.

Atendiendo a estas especificidades, sostendré que las ocupaciones de tierra en Resistencia pueden considerarse movimientos sociales urbanos, en función de los efectos territoriales y políticos que producen sobre la ciudad, sobre el espacio, etc. Si bien uno de los casos estudiados -la ocupación de la Rubita- concluyó con el desalojo de los ocupantes, a partir de este proceso se empezó a instalar el tema y una de las consecuencias que tuvo esta "ocupación fallida" es que en lo sucesivo, el Estado —en este caso el gobierno provincial- movilizó recursos para regularizar las ocupaciones o al menos ofrecer una alternativa a los ocupantes. A partir de ese caso de ocupación, todas las que se produjeron posteriormente han sido regularizadas o están en vías de regularización jurídica. Es decir que, en cierta manera, están imponiendo al estado provincial la implementación una política de tierras y viviendas.

Otro punto es que si bien el móvil es la reivindicación basada en la obtención de "un lugar para vivir", es decir, terrenos donde construir sus viviendas en un lugar en el que puedan desarrollar sus estrategias de supervivencia, en la gran mayoría de los casos consistente en trabajos precarios, las justificaciones que los ocupantes dan a los medios trascienden la reivindicación e implican la puesta en juego de otros valores como la dignidad, la necesidad de una inserción social más plena, etc.

En lo relativo a la expresión política que adquieren las ocupaciones propiamente dichas y movilizaciones de los "sin techo", es notable que ocupan un espacio en la escena social y política, y en ciertos momentos incorporan a otros sectores de la población, aunque después se disuelva el movimiento hasta su reaparición o aparición de nuevos movimientos, etc.

Así vemos, en diferentes niveles de compromiso y alianza política, cómo se manifiestan apoyos a los grupos de pobladores ocupantes por parte de organizaciones dedicadas a los derechos humanos,[19] artistas,[20] etc. También en determinado momento se articulan a los reclamos de otros grupos de pobladores para producir movilizaciones en conjunto.[21] Y en otro nivel, la incorporación a organizaciones políticas pre-existentes a la ocupación.[22]

\section{LA OCUPACIÓN DE “LA RUBITA”: UN ANTES Y UN DESPUÉS}

La ocupación de terrenos, como forma de resolución habitacional de los sectores más desfavorecidos de la sociedad, ha adquirido nuevas configuraciones en varios aspectos que quiero señalar.

En principio se trata de una práctica que si bien no es nueva, ha tomado una frecuencia casi cotidiana. Permanentemente se están produciendo asentamientos de población —en grupos más o menos numerosos- en distintos terrenos.

Espacios intersticiales que circundan a los barrios FONAVI o barrios ya consolidados, que cuentan con cierta infraestructura o cercanía a infraestructura, localizados en zonas relativamente altas - 
Resistencia padece, por razones de implantación, de inundación por lluvias- y ubicados estratégicamente desde el punto de vista de obtención de trabajos temporarios o "changas".

Otro aspecto que es nuevo en los procesos de ocupación de tierra urbana es el relativo a la forma de organización espacial. Los asentamientos de población en terrenos urbanos de décadas anteriores se caracterizaban por ser irregulares tanto desde el punto de vista jurídico, como desde el punto de vista físico espacial.

En la siguiente descripción de un diario local leemos:

El lote fue ocupado espontáneamente por los vecinos, sin planificación ni justicia en la distribución de la tierra. Para muchos, es necesario ingresar por el terreno de su vecino para poder llegar a su vivienda. No hay calles trazadas, sino senderos irregulares que penetran en el corazón del bloque.[23]

Corresponde a una ocupación producida en 1982-'83 en la que un grupo de vecinos ante la catástrofe que significó la inundación de aquella época, ocupó en forma compulsiva un terreno de propiedad privada, organizados por el intendente de una administración de facto. Fue una ocupación de "emergencia" que se prolongó dieciséis años, hasta que se efectivizó la expropiación decretada por el intendente de ese momento.

La imagen que tenemos de las llamadas "villas miserias" o simplemente "villas" responde a esta forma de organización espacial, al menos mientras dure el asentamiento jurídicamente irregular, una vez que los aparatos del estado deciden la intervención para regularizar dominialmente, se procede a la demarcación regular al estilo de lotes individuales.

En las ocupaciones producidas más recientemente, en cambio, se pretende rudimentariamente seguir una lógica de parcela demarcada con un trazado regular "como si..." fuera un barrio planificado, en un intento explícito de alejarse de la tradicional imagen de la "villa miseria". En relación con esto presentaré dos ejemplos:

Los vecinos, en el proceso de asentamiento, se fueron dando un plan de ordenamiento voluntario, y de acuerdo a una disposición tentativa que lograron a partir de un plano que la empresa constructora propietaria les cedió, cuando éstos gestionaban una supuesta compra directa. Adecuaron a ésta el trazado de los alambrados, regularizando las características de los terrenos (tamaños y formas), previeron la apertura de calles semipúblicas, teniendo que mudar muchas familias sus casas ya construidas (algunas de ladrillo y mezcla, con piso, etc) a los nuevos terrenos que hoy les corresponden (completaron una manzana que estaba vacía sólo con los traslados, al normalizar los terrenos).[24]

La cita relata el proceso de "regularización" de Villa Luzuriaga Se trata de un asentamiento que se produjo a lo largo de muchos años hasta que los vecinos lograron articular una organización vecinal importante y empezaron a gestionar la propiedad del terreno por medio del mecanismo de expropiación, después de gestionar la compra directa a los propietarios (una empresa constructora).

A continuación vemos uno muy reciente, el Lote 133:

Los ocupantes inmediatamente se organizaron en una Comisión Vecinal, tenían un plano hecho a pulso, con las delimitaciones de lotes contemplando pasillos intermedios entre cada parcela.[...].[25]

Una diferencia en ambos casos: en Villa Luzuriaga (ocupación que se inició en 1986) organizarse en el terreno en la forma de un lote por familia llevó muchos años, e implicó la re-ubicación de 24 familias que habían construido sus casillas en el lugar destinado al trazado de la calle pública, como en una "villa".

En el caso del Lote 133 (producido en 1998), en cambio, desde el momento mismo de la ocupación, los ocupantes tuvieron conciencia de la conveniencia de asentarse organizando los lotes individuales y 
dejando el espacio para calles públicas, en esto se diferencian de las "villas" y se organizan espacialmente como un "barrio".

Otra cuestión refiere a la forma de ocupación, a la manera como se instalan. En los casos más antiguos las familias se van asentando a lo largo de muchos años en el terreno.

En las más recientes, en cambio, las familias se instalan en pocos días. Esto es importante considerarlo, por un lado, desde el punto de vista de la constitución de las redes sociales que se van estableciendo entre los vecinos ocupantes. En las más recientes, es como si las redes estuvieran constituidas de antemano.

Por otro lado, la forma cómo se instalan en el terreno interesa también por las reacciones de otros actores sociales en relación con la ocupación. En las ocupaciones mas recientes, en las que un numeroso grupo de familias (cientos) se instalan en un terreno y empiezan a construir sus casillas, a unos pocos días, casi simultáneamente con la toma del terreno, se activa un conjunto de dispositivos de represión, que más que real es simbólica, pero necesaria para reafirmar las posiciones específicas de cada participante.

Leemos en los diarios locales:

“...400 efectivos de gendarmería nacional apostados en el ingreso al terreno y una causa federal iniciada en 24 horas, en las tareas de cuidar que no se produzcan conflictos entre los ocupantes, persuadir para que las familias dejen pacíficamente el predio e impedir que en el transcurso de las acciones judiciales se asienten mas familias, etc."[26] 0 también, "Ios ocupantes desalojaron los terrenos tras la firma de un acta en la que se comprometen a abandonar el lugar pacíficamente". [27]

O, “...Un guardia policial se instaló en el lugar y montó un 'destacamento' al lado de uno de los ranchos del margen del terreno 'No los molestan'. Su función es 'mantener el orden' - lo cual es solo formal porque los ocupantes ilegales son extremadamente pacíficos- e impedir que las familias sigan ingresando con elementos para levantar sus chozas o muebles domésticos".[28]

Por último, otro aspecto novedoso, que quiero señalar, es la intervención de los medios masivos (prensa local y en algunos casos, nacional) que van relatando día por día los pormenores de las ocupaciones y les otorgan una nueva trascendencia dando a conocer la posición de los distintos agentes sociales involucrados.

Como sabemos, la prensa no es un agente neutro, expresa sus propias definiciones políticas dándole voz a ciertos y determinados actores más que a otros, etc. No obstante, informa sobre los hechos y fundamentalmente permite que los protagonistas se expresen y expongan ante el resto de la sociedad sus razones, posiciones, necesidades, recursos, y disponibilidades, etc. y además sus representaciones vinculadas a lo que significa vivir en la ciudad.

La ocupación de los terrenos de propiedad del Ejército Nacional conocidos como La Rubita, inaugura estas novedades, ya que fue la primera vez que "espontáneamente" sin apoyo oficial, un numeroso grupo de familias produce una ocupación.

El 16 de marzo del 1997 se produjo la ocupación de un terreno de 64 has., ubicado al SE del Gran Resistencia, por parte de casi 500 familias, que en pocas horas armaron sus rudimentarias viviendas y permanecieron en el lugar hasta el día 22 en que desalojan los terrenos, a causa de un pedido que gestionó el Ejercito Nacional, propietario del terreno, ante la Justicia Federal.[29]

En el transcurso del breve periodo que duro la ocupación (una semana) se pusieron en marcha toda clase de mecanismos jurídicos y políticos por lo que el caso alcanzó gran repercusión social y política.

Los ocupantes sostenían que la ocupación fue espontánea y originada en la toma de conocimiento, por un lado, de que había allí una familia asentada desde hacia varios meses y nunca "fue molestada" para que desaloje, y por otro, de que esas tierras, si bien eran de propiedad del Ejercito, pasarían a manos de la Municipalidad de Resistencia y ellos podrían conseguir la tenencia, y tener sus casas por autoconstrucción progresiva.[30] 
A diferencia del Juez Federal y el Gobierno Provincial que insistían en la hipótesis de la toma organizada y sobretodo "instigada con fines políticos". Mientras el primero orientaba sus investigaciones del expediente en ese sentido, el Gobierno provincial solicitaba al Juez que se encuentre a los instigadores y dirigía por los medios masivos de comunicación acusaciones a funcionarios del partido opositor de promover la ocupación.

En tanto, por intermedio del Plan Tierras les ofrecía a los ocupantes otras localizaciones, mas alejadas del centro de la ciudad pero en disponibilidad del Gobierno provincial, en la interpretación de que el conflicto debe ser resuelto dentro del Gran Resistencia —área metropolitana - que comprende los municipios de Barranqueras, Vilelas, Fontana y Resistencia,[31] lo que daría posibilidad de conseguir tierras.

El PJ, del mismo signo político del gobierno nacional, opositor al Gobierno Provincial, no tuvo una actitud de bloque. Los acusados, negaba las acusaciones y respaldaba la acción de los ocupantes, a la vez que prometían interceder ante el Ejercito el traspaso del terreno. El intendente, repudiaba la usurpación y manifestaba la necesidad de crear un banco de tierras para sanear la cuestión dominial.

Por su parte, otros agentes intervenían: y la entidad que nuclea a todas las organizaciones Vecinales apoyaba a los ocupantes.

La entidad que nuclea a los agentes inmobiliarios dirigía sus criticas al Concejo Municipal -órgano legislativo del municipio- por las restricciones de el código urbano de Resistencia para la realización de "loteos económicos".[32]

Este cruce de acusaciones y desmentidas, ofrecimientos, apoyos y repudios, más la inmediata movilización de funcionarios y dirigentes políticos de todas las instancias gubernamentales para frenar y reprimir primero la afrenta contra la propiedad privada - con 400 efectivos de gendarmería nacional apostados en el ingreso al terreno y una causa federal iniciada en 24 horas-, y después para dar una respuesta que permita obtener un importante rédito —dado el numeroso grupo de familias tomadoras-, desnuda que este hecho puso en crisis la gobernabilidad local, y que podía ser un precedente importante que había que evitar.

Después de días tan tensos, finalmente, los ocupantes desalojaron los terrenos tras la firma de un acta en la que se comprometieron a abandonar el lugar pacíficamente.

Tras el desalojo de las familias ocupantes de la Rubita, muchos dejaron el lugar inmediatamente y otros siguieron reclamando esas tierras, "apoyados" por un concejal (PJ) y un Diputado (PJ), a su vez ese grupo se dividió constituyendo dos Comisiones Vecinales.

Una de esas Comisiones (formada ya por un grupo minoritario de las familias ocupantes iniciales) acepto el ofrecimiento del Ejecutivo Provincial (UCR) de asentarse en un terreno que el Gobierno de la Provincia compró en el límite de los municipios de Pto. Vilelas y Resistencia, para la cual debían los pobladores "juntar" al menos 400 familias; cumpliendo con esto, se difundió la noticia en los medios de que se estaba "buscando a las familias que habían tomado La Rubita", de esta manera, se reunió el grupo de vecinos beneficiarios actuales del barrio llamado Ciudad de Los Milagros.[33]

Aunque en los medios se presente que allí fueron reubicadas las familias "sin techo" que ocuparon hace un año los terrenos de La Rubita, de las 500 familias que ocuparon la Rubita, bastante menos de 100 son las que actualmente viven en la primera parte que se construyó del barrio.[34]

En este ejemplo de ocupación "fallida" - ya que los ocupantes fueron desalojados - podemos ver como opera la interacción de algunos de los sujetos definidos antes como agentes urbanos: el estado -representados por distintos organismos_, el capital —centralmente representado por la cámara inmobiliaria - y la población movilizada —en este caso los ocupantes- Esta ocupación sienta los precedentes e implica un conjunto de enseñanzas para otras ocupaciones.[35] 


\section{CONCLUSIONES}

He intentado demostrar que las ocupaciones de tierra producidos en los últimos años en Resistencia, a partir del caso de ocupación de la Rubita, caracterizadas por mayor frecuencia, masividad, organización regular de los terrenos, e intervención de los medios masivos de comunicación, son complejos fenómenos que requieren ser abordados como una práctica social, como un hecho social a la vez que como un fenómeno territorial, ya que constituyen una manifestación de disputas sobre la legitimidad de integrarse al espacio urbano, en el sentido físico y simbólico.

Expresan, por un lado, la intención de los ocupantes de participar en el espacio urbano como ciudadanos, es decir de pertenecer a una totalidad social.

En teoría, el de ciudadano es un rol social nivelador que promete una situación igualitaria, acaba con las singularidades e inaugura una entidad general y abstracta (Dumont: 1987). En la práctica, no obstante, esa universalidad se desvanece y la sociedad funciona en forma desigual y jerarquizada, en tanto la condición de ciudadano está atravesada en lo concreto y en lo simbólico por la situación jurídica de propietario, el papel de ciudadano es así un punto de partida, para algunos, y de llegada para otros.

Por otro lado, las acciones de los pobladores para resolver, mediante la ocupación de tierras urbanas, su inserción en la ciudad, expresa también la transformación (o retirada) de las políticas del estado en materia de vivienda, que se enlaza con la transformación de las políticas del estado en otros aspectos sociales (educación, salud, producción), que se empezaron a gestar a fines de los '70 y '80 y se están visualizando plenamente en la actualidad.

Lo que quiero significar es que la nueva forma en que se están produciendo las ocupaciones de tierra, en su expresión política, tanto como en su expresión material o territorial, es un indicador de profundas transformaciones sociales y debemos empezar a pensarlas como una nueva institución urbana: la falta de empleo y reacomodación de las ingerencias de los distintos niveles del estado (nacional, provincial y municipal), configuran una realidad compleja, que en una ciudad como Resistencia, capital de una de las provincias más pobres de la Argentina, con recurrentes inundaciones pluviales y por desborde de los ríos, y una prolongada crisis de producción agrícola, adquiere particularidades más complejas aún.[36]

Plano 1

Gran Resistencia. Ocupaciones de tierra: casos de estudio.

Elaboración propia. 


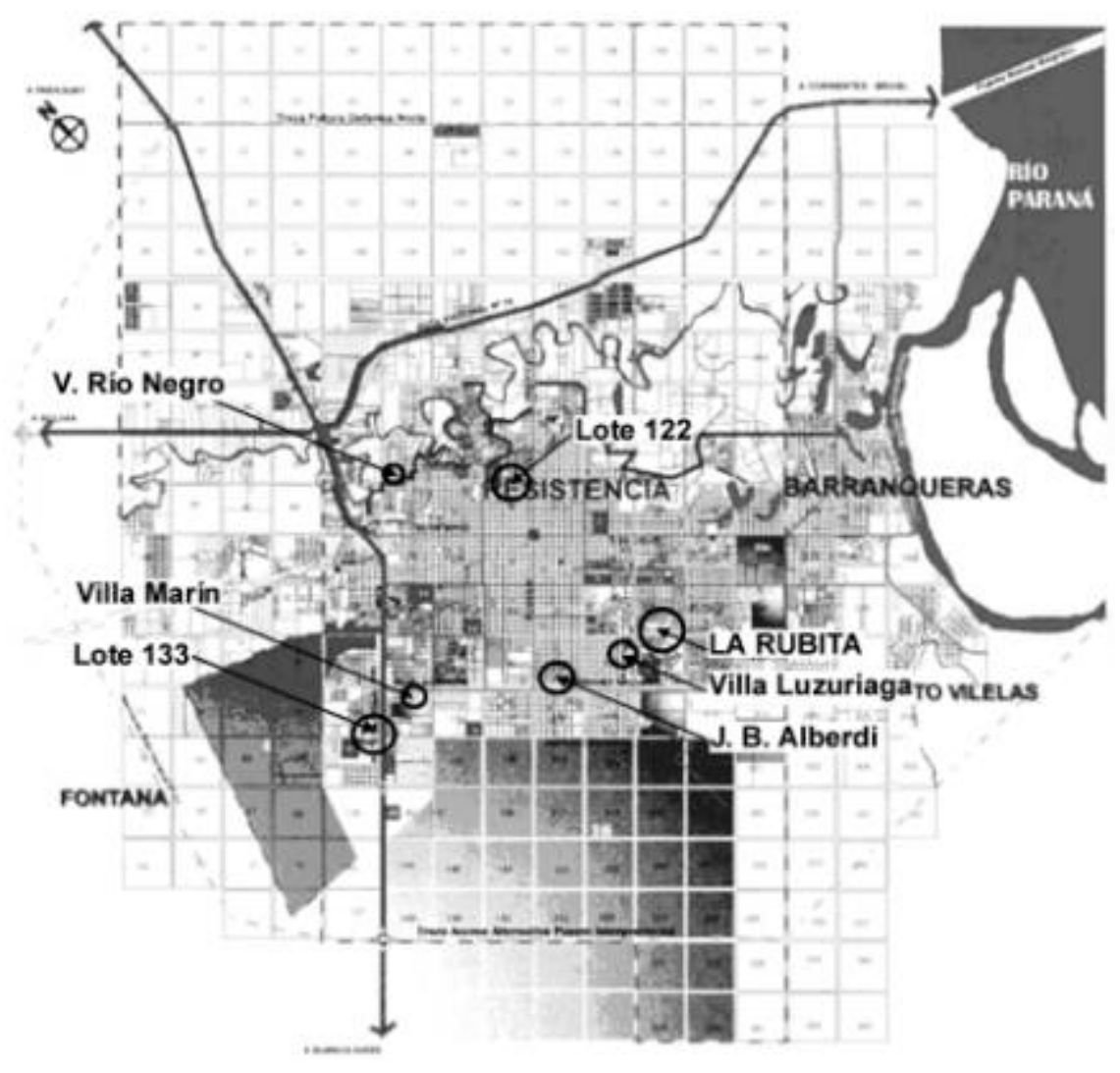

\section{BIBLIOGRAFÍA}

\section{BARRETO, M.}

1993. "Inundaciones en el Gran Resistencia durante 1982-83. Comportamiento del sistema urbano y la Renta durante la crisis". En: Cuaderno 1 de la Cátedra De Sociología Urbana, FAU, UNNE, Argentina, (7-47), BENÍTEZ, M.

2000. "De la Villa Al Barrio. Hipótesis sobre construcción de identidades derivadas de la ocupación de tierras urbanas". En CAAS: Congreso Argentino de Antropología Social, Mar del Plata. Publicación en CD ROM.

2001. "Procesos de ocupación de suelo urbano en el Gran Resistencia. 1983-1998. Presentación de los casos de estudio". En: Rodríguez y Rozé (coord.). Ciudades Latinoamericanas: Una Visión Social Del Urbanismo. Fomento universitas. Guerrero. México.

\section{CASTELLS, M.}

1978. La cuestión urbana. Siglo XXI. México

1983. The city and the grassroots: a cross cultural theory of the urban social movements, Eduard, Arnold, London. 1988. Crisis Urbana, Estado Y Participación Popular. Colegio de Arquitectos de Cochabamba. Bolivia.

CLAVAL, P.

1966. Espacio Y Poder. Fondo de Cultura Económica. México

CORAGGIO, J. L.

1988. Consideraciones teórico metodológicas sobre las formas sociales de organización del espacio y sus tendencias en América Latina. CIUDAD. Quito.

DE MATTOS, C.

1987. Mito y realidad de la planificación regional de los países capitalistas latinoamericanos. Mimeo, Santiago. DUMONT, L.

1987. "Marcel Mauss: una ciencia en devenir". En: Ensayos Sobre El Individualismo. Ed. Alianza Universidad. Madrid

ELIAS, N.

1982. La Sociedad Cortesana. FCE, México.

FLORES-ALATORRE, S. 
1994. "Una revisión de las principales corrientes teóricas sobre el análisis urbano". En: Anuario de Estudios urbanos, No 1, 1994, (73-115). UNAM, Azcapotzalco.

HARVEY, D.

1990. La condición de la posmodernidad. Investigación sobre los orígenes del cambio cultural. Amorrourtu, Buenos Aires.

ISUANI, E.; LO VUOLO, TENTI FANFANI, E.

1991. El Estado Benefactor: Un Paradigma En Crisis. Miño y Dávila /CIEPP. Bs. As.

LOMNITZ, L.

1975. ¿Cómo sobreviven los marginados?. Siglo XXI. México.

LOJKINE, J.

1979. El marxismo, el estado y la cuestión urbana. Siglo XXI. México.

MINUJIN, A.; KESSLER, G.

1995. "La Nueva Pobreza" En: Los ‘90 En La Argentina. Ed. Planeta. Buenos Aires.

NUÑEZ, A.

2000. Morfología Social de Mar del Plata 1874-1990. Grafikart. Bs. As. Argentina.

ROZÉ, J.

1993. "Desastres recurrentes y conflictos sociales. Tomas de viviendas en el marco de las inundaciones de 1983 y

1986". En: Cuaderno 1 de la Cátedra De Sociología Urbana, FAU, UNNE, Argentina (11-43).

SBROCCO, M.

1999. "Asentamientos: Entre La Estrategia Y La Gestión. Salta 1997". En: Rabey, M. y Jerez, O. 1999. Procesos de Urbanización en la Argentina. La mirada antropológica, UNJu, Jujuy.

TOPALOV, C.

1979. La urbanización capitalista. Algunos elementos para su análisis. Edicol. México.

YUJNOVSKY, O.

1984. Claves Políticas del Problema Habitacional Argentino: 1955-1981. GEL, Bs. As.

\section{Fuentes:}

Diarios: "Norte" desde 01/01/98 a 01/10/98 y "El diario" desde 01/01/98 a 01/10/98

Entrevistas a ocupantes, informantes calificados que participaron en la regularización dominial.

Informes: CIET, 1989; IIDVi, 1998; PAGV, 1999.

Informe SIEMPRO, Diagnóstico social de la Provincia del Chaco.

[1] El concepto de ciudad intermedia está basado en Herzer, H. (1997), el cual alude a características cuantitativas: tamaño de la población —entre 50 mil y 500 mil habitantes-, densidad de población, extensión física, influencia del grado de urbanización del país con relación a estos centros, umbral de diversificación de las actividades, contribución a la producción nacional o regional, proporción de su fuerza de trabajo en tareas no agrícolas, etc. Además el concepto implica también características cualitativas: menor nivel de complejidad institucional relativo - no son sede del gobierno nacional— solo de gobierno provincial o municipal, etc.

[2] Esta ocupación fue organizada por un intendente de facto ante la emergencia de las inundaciones catastróficas de los años '82'83; por eso se trata de un caso muy masivo en que la instalación fue muy rápida y contó con el apoyo "oficial" de la municipalidad. La expropiación se hizo efectiva dieciséis años después, tras amenaza de desalojo.

[3] Esto es parte de los resultados de la investigación exploratoria sobre casos de ocupaciones producidas en los últimos quince años en Resistencia. Ocupaciones de tierra urbana en Resistencia 1983-1998: Estudio de casos, que forma parte de la Tesis de mi autoría para la Maestría en Epistemología y Metodología de la Investigación. Inédita.

[4] La población de Resistencia era en 1991 de 291.000 hab. (INDEC).

[5] De ello da cuenta un informe oficial del Plan Tierras, organismo dependiente del Ministerio de Transporte, Obras y Servicios Públicos de la Provincia del año 1995. Es necesario aclarar que el término Irregular alude a la situación dominial de la los ocupantes con relación al terreno que ocupan, hace referencia a la ilegalidad. Sin servicios significa que no cuentan con el tendido de red agua potable, luz eléctrica y recolección de residuos. Ambas condiciones están ínter determinadas, dado que la condición de ilegalidad de los ocupantes es el argumento que los organismos del estado emplean para justificar que los asentamientos no cuenten con el tendido de infraestructura. De ello da cuenta un informe oficial del Plan Tierras, organismo dependiente del Ministerio de Transporte, Obras y Servicios Públicos de la Provincia del año 1995.

[6] Fondo Nacional de la Vivienda. 
[7] Es conveniente señalar que el Estado benefactor, que se insinúa a partir de la crisis del '29, se consolida después de la segunda posguerra interrelacionado a las medidas económicas del Keynesianismo. Por ello la crítica que ataca a los fundamentos económicos del Keynesianismo involucra a las instituciones del Estado benefactor.

Con estado benefactor estoy aludiendo a un paradigma de organización estatal actualmente en crisis. Aunque en América Latina, la implementación de este paradigma tiene particularidades diferentes a los países centrales, en la medida en que nuestras economías revisten un carácter de dependientes de las de aquellos, entre otras razones vinculadas a las tradiciones políticas.

[8] El concepto de seguridad social en las políticas del Estado reemplazó a la beneficencia pública e implicó un conjunto de instituciones que garantizaron servicios sociales a los trabajadores y sus familias, y se empezó a implementar desde la segunda posguerra. Por ej. Vacaciones pagas, servicios médicos, jubilación, etc.

[9] En este sistema el beneficiario inicia el pago de la que será su vivienda mientras ésta se está construyendo, supone una capacidad de ahorro que los sectores de población del sector informal no pueden asumir.

[10] Las villas de emergencias se caracterizan por la ocupación de tierras fiscales principalmente, No hay reivindicación por la compra de los terrenos. Organización territorial aleatoria por agregación de lotes irregulares. Los asentamientos se distinguen de las villas de emergencias: igualmente son ocupaciones de tierra privadas y fiscales, pero con interés en la compra de los terrenos. Organización territorial de acuerdo a las normas urbanas y definición de lotes estandarizados. Sbrocco, M. E. (1999).

[11] Estoy utilizando aquí la definición de marginalidad de Lomnitz (1975), que considera la combinación de exclusión estructural y pauperización.

[12] Esto ha sido puesto de relieve en numeroso estudios. Ver, por ejemplo, la Reunión Regional de América Latina y el Caribe preparatoria de la Conferencia de las Naciones Unidas sobre los Asentamientos Humanos (Hábitat II) realizada en Santiago de Chile en 1995. También el Informe sobre Desarrollo Humano publicado por el Senado de la Nación Argentina 1997.

[13] Localmente denominadas "changas".

[14] Según un diario local que da cuenta de una ocupación en particular. "El Diario" 21/01/98.

[15] Diario "El Diario" 31/01/98.

[16] Se denomina "mejora" a una precaria construcción realizada en una porción de terreno ocupado ilegalmente. Algunos ocupantes realizan una suerte de acción de agentes inmobiliarios; ocupan un terreno, hacen una casita rudimentaria y luego la venden para asentarse en otro lugar y volver a vender, etc. La estrategia de supervivencia es la diferencia que van generando en cada venta.

[17] Ver Núñez: 2000.

[18] En Castells (1983), este autor hace una "autocrítica" de sus trabajos anteriores en este sentido y se separa del marxismo estructuralista (al cual él mismo había realizado importantes contribuciones). Razón por la cual algunos autores lo incluyen en la corriente de sociología urbana neomarxista. Ver por ejemplo, Flores-Alatorre: 1994.

[19] Por ejemplo la agrupación HIJOS que manifestó su apoyo a uno de los grupos de ocupantes. Diario "El diario" 22/5/98.

[20] Por ejemplo el artista León Gieco. Diario "El diario" 22/5/98.

[21] Por ejemplo el reclamo frene a la empresa SAMEEP proveedora del Agua potable en la provincia que agrupó a vecinos de un barrio de viviendas FONAVI -las 240 viviendas-, a la Federación de Entidades Vecinales, y ocupantes "sin techo" del lote 133. Diario Norte 4/10/98.

[22] Como por ejemplo la Federación de Entidades Vecinalistas.

[23] Diario "El diario" 25/06/98.

[24] En relación con el proceso de regularización de Villa Luzuriaga.

[25] En relación con el proceso de regularización del Lote 133, el subrayado es mío.

[26] En relación con la ocupación de La Rubita.

[27] En relación con la ocupación de La Rubita.

[28] Diario "El Diario" 17/05/98. Con relación a la ocupación del Lote 133.

[29] En esta causa tuvo intervención el Juez Federal por ser el propietario del terreno un aparato del estado de la órbita nacional, por esta misma razón tuvo intervención la fuerza de Gendarmería nacional en las tareas de "cuidar que no se produzcan conflictos entre los ocupantes, persuadir para que las familias dejen pacíficamente el predio e impedir que en el transcurso de las acciones judiciales se asienten mas familias, etc." según informan los diarios locales en las crónicas del proceso de ocupación.

[30] Un grupo de representantes de los ocupantes participaron en un panel de presentación de la problemática por invitación de la Cátedra de Sociología urbana de la Universidad del Nordeste y allí expusieron sus perspectivas (año 1997).

[31] Dos de ellos con intendentes del partido del gobierno de la provincia (Vilelas y Fontana) y dos (Barranqueras y Resistencia) con intendentes del partido opositor.

[32] Consisten en la compra de tierras privadas a través de cuotas a largo plazo, y organización territorial de acuerdo a normas urbanas con lotes estandarizados. Sbrocco, M. E. (1999). En relación a esto leemos en el diario "Norte" (15/03/98) al Presidente de la Cámara Inmobiliaria del Chaco "desde hace año venimos pidiendo que el Estado municipal de Resistencia se retire, que no intervenga de manera tan arbitraria, elitista y antojadiza, en el tema de los loteos.[...] desde hace 20 año no hay un loteo para gente de escasos recursos. [...] un lote de $\$ 50$ por mes en Resistencia. Esto sucede porque exigen que el propietario haga todas las infraestructuras que tienen que hacer SAMEEP Y SECHEEP. Con esto, la municipalidad es también la única culpable de que haya intrusos por todos lados en la ciudad. La gente tiene vocación de comprar su lotecito y la municipalidad no le da posibilidades de adquirirlo. Sabemos que hay decisión política de revertir esa situación, pero el consejo municipal no lo quiere tratar.... Hemos encontrado muy buena receptividad por parte del Intendente González. Pero cuando el tema entra al Concejo se convierte en un 
agujero negro y no es tratado. Esta es la lucha que la Cámara Inmobiliaria del Chaco esta sosteniendo con los Concejales de Resistencia".

[33] El barrio Ciudad de Los Milagros es un conjunto habitacional que el Gobierno de la Provincia esta construyendo. Se trata de 400 viviendas - ejecutadas por empresas constructoras - y plazoleta, escuela, puesto policial, centro de salud y un centro comunitario. Esto mediante la aplicación del Plan AIPO; en el que intervienen en forma coordinada diferentes áreas del Estado provincial: la Secretaria de Desarrollo Social, Plan de Tierras, Empresa de Energía eléctrica (Secheep), Empresa de provisión de Agua potable (Sameep), el Instituto Provincial de la Vivienda (IPDUV), y una entidad de coordinación del estado provincial con una entidad financiera externa (SUPCE).

[34] Esta información se obtuvo en un conjunto de entrevistas realizada por estudiantes de la Cátedra de Sociología urbana de la FAU, UNNE, en 1998, a los pobladores del barrio Ciudad De Los Milagros.

[35] Esto además fue declarado por un dirigente vecinalista en una Disertación en la Cátedra de Sociología Urbana (FAU, UNNE, año 2000). Si bien el campo empírico de esta investigación abarca hasta el año 1998, siguiendo procesos de ocupación de tierra que se están produciendo desde esa fecha, se observa que se repite este "patrón" de asentamientos.

[36] La provincia del Chaco, que cuenta con una extensión de $99.633 \mathrm{Km}_{2}$ y tenía un total de 839.677 hab. en 1991, presenta situaciones deficitarias en la casi totalidad de los indicadores analizados en el "Informe de situación social № 7, Diagnóstico de la Provincia del Chaco" realizado en base a la metodología de brechas sociales. SIEMPRO, 2000. Chaco, al igual que las otras provincias del NEA se ubica como la jurisdicción con mayor déficit habitacional y de acceso a servicios. Se define como un área geográfica con alto riesgo o vulnerabilidad social (son definidas así las zonas con mas del $30 \%$ de hogares con Necesidades Básicas Insatisfechas -NBI-. Este indicador mide calidad de la vivienda, condiciones sanitarias, escolaridad e ingresos).

Se incluyen en el concepto de vulnerabilidad social a barrios con población empobrecida en términos de ingresos, o con alta tasa de desempleo, o desocupación, que habitan en viviendas no precarias y con servicios básicos, como por ejemplo los conjuntos habitacionales de producción estatal (según datos SISFAM). Mas de la cuarta parte de la población del Chaco continúa viviendo en zonas rurales, siendo la segunda proporción mas alta de la región NEA, que supera en 15 puntos al total del país.

En las últimas dos décadas el porcentaje de población rural descendió en la provincia mas lentamente que en el resto de la región NEA, pero a un ritmo más intenso que en el total del país.

La población urbana creció en Chaco de 60,9 \% en 1980 a 70,3 \% en 1991. Específicamente en el departamento Capital —donde se encuentra Resistencia-, como consecuencia directa de la expulsión de población rural que se asienta en sus bolsones de pobreza, ha ido en un constante proceso de urbanización que alcanza en el año 1960 el 86,4\%. En el año 1970 el 91,3\%. En 1980 el 95,2\% y en el año 1991 98,7\%, Ilegando a alcanzar Resistencia el 99,2\% para una población aproximada a los 291.000 habitantes. (INDEC. 1991). La tasa de actividad, del $30 \%$ es 16 puntos menor que el total del país. No obstante la incidencia del sector público en la generación de empleo, mas de la cuarta parte de los empleos, mas del 50\% de los ocupados se inserta en el sector informal. En el último censo nacional (1991) el parque habitacional de la provincia registra un $40 \%$ de viviendas deficitarias, es decir que no cuentan con provisión de agua en el interior de la vivienda, no disponen de recinto sanitario (retrete con descarga de agua) tienen piso de tierra o contrapiso sin aislación de humedad. $17 \%$ de viviendas rancho y casillas, las primeras, propias de las áreas rurales, tienen generalmente paredes de adobe, piso de tierra y techo de paja; las casillas, propias de las áreas urbanas generalmente están construidas con material de desecho (esta es la tipología de las casas que se encuentran en los asentamientos originados en ocupación ilegal de la tierra). $16 \%$ de hogares con hacinamiento crítico es decir con mas de 3 personas por cuarto, excluidos la cocina y el baño. $9 \%$ de hacinamiento mitigado es decir mas de 2 y hasta 3 personas por cuarto, excluidos la cocina y el baño. $29 \%$ de tenencia irregular de la tierra (en 1991). No obstante el déficit en materia de vivienda ha tenido una evolución favorable entre 1980 y 1991, hipotéticamente ligada al avance en el proceso de urbanización, pero estuvo lejos de eliminarse. Con déficit de vivienda se hace referencia no sólo a la cantidad de unidades físicas faltantes, sino también a la condición de accesibilidad a los servicios e infraestructura básica. (Yujnovsky: 1984) 